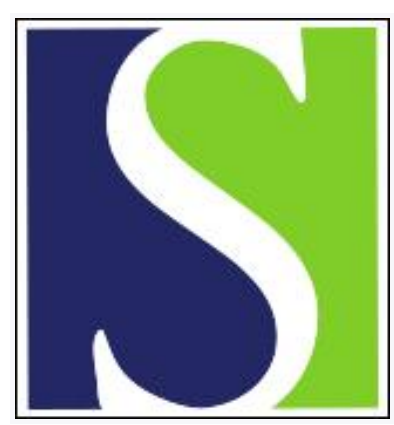

Scand J Work Environ Health 1990;16(2):113-120

https://doi.org/10.5271/sjweh.1809

Issue date: 01 Apr 1990

Mortality of workers in the British cotton industry in 1968-1984.

by Hodgson JT, Jones RD

Affiliation: Epidemiology and Medical Statistics Unit, Merseyside, United Kingdom.

The following article refers to this text: 2010;36(6):499-508

This article in PubMed: www.ncbi.nlm.nih.gov/pubmed/2353194 


\title{
Mortality of workers in the British cotton industry in 1968-1984
}

\author{
by John T Hodgson, MSc, ${ }^{1}$ Robert D Jones, FFOM ${ }^{1}$
}

\begin{abstract}
HODGSON JT, JONES RD. Mortality of workers in the British cotton industry in 1968-1984. Scand $J$ Work Environ Health 1990;16:113-20. The mortality of 3458 cotton industry workers originally enrolled in a study of respiratory symptoms in the period 1968-1970 was followed to the end of 1984 . Both the total mortality and the mortality from respiratory disease were less than expected, and they both decreased as length of service increased. However, for the subjects who initially reported byssinotic symptoms, the mortality from respiratory disease was slightly raised overall, and it increased with length of service. These patterns of mortality indicate a survivor effect (ie, a tendency for those with respiratory weakness to leave the industry), together with a long-term effect reflected in respiratory mortality on the health of those workers susceptible to the effects of cotton dust. The mortality from lung cancer was lower than expected, and it decreased with length of service. This finding is consistent with other observations that exposure to cotton dust may reduce the risk of lung cancer.
\end{abstract}

Key terms: byssinosis, cotton dust, lung cancer, respiratory disease.

Respiratory disease in cotton workers has been the subject of much research since the description of byssinosis and its association with exposure to cotton dust appeared. Recently there has been considerable debate about the clinical and pathological nature of byssinosis and the natural history of the disease (1-4). In particular the element of chronic, irreversible respiratory disablement has been questioned.

During 1968 - 1970 a morbidity survey of cotton workers in northwest England was carried out, and it was reported on by Fox et al in $1973(5,6)$. A subsequent mortality study of this population was seen as one way of examining the long-term health effects of exposure to cotton dust and their relationship to byssinosis. This paper reports the mortality of that population to the end of 1984 and examines the results in the light of the current byssinosis debate.

\section{Subjects and methods}

\section{Subjects}

The study population consisted of all cotton workers reported on in the prevalence morbidity survey of 1968-1970. A full description of the results of that survey is given in the earlier reports $(5,6)$. The following paragraphs, taken from the first report (5), describe the selection of the study population.

\footnotetext{
' Health and Safety Executive, Merseyside, United Kingdom.
}

Reprint requests to: Mr JT Hodgson, Health and Safety Executive, Epidemiology and Medical Statistics Unit, Magdalen House, Stanley Precinct, Bootle, Merseyside L20 3QZ, United Kingdom.
The survey was carried out in two stages. In the first (1966-68), 35 cotton mills were visited, 26 spinning coarse and 9 medium cotton. All were situated in the Rochdale, Oldham, Ashton area. In the second (1968-70) 29 mills, 21 coarse and 8 medium, were re-visited two years after the initial visit and in the same week in the year. In addition, 13 coarse mills, 2 medium mills, and 2 fine mills were visited in other areas of the country, namely, Lancashire, West Riding of Yorkshire, and Scotland. Five of the medium mills included between $30 \%$ and $40 \%$ rayon with their cotton and two others did so occasionally. At all the mills operatives in the cardrooms and blow-rooms were examined in the middle of the working week. In 11 mills ( 6 coarse, 3 medium and 2 fine) the operatives in ring and winding rooms were also examined.

Of the total population available, approximately $10 \%$ refused to co-operate. A further $13 \%$ had to be excluded. Some of these were absent at the time when the mill was visited and the rest were seen but had to be excluded either because of ethnic difficulties (Cotes and Malhotra, 1965; Cotes, 1968) [7,8] which made prediction of normal values for ventilatory function impossible, or because of failure to collect all the information necessary for the analysis. Of the $77 \%$ included in the analysis, 2,316 were seen on the first occasion and 2,556 on the second. As 886 were seen on both occasions the total population for analysis was 3,986 . In order to be sure that the population excluded did not include an exceptionally high proportion of disabled persons the frequency of persons drawing disablement benefit was compared in the included and excluded groups. No difference was found [p 43].

In 1971-1974 a third round of survey examinations was undertaken. No new subjects were included, but an attempt was made to trace all those seen in either of the previous rounds, whether or not they were still working in the cotton industry. A total of 1497 subjects was seen. 
At the end of this exercise all available survey records were entered onto a computer file, and identification details were sent on cards to the National Health Service Central Register (NHSCR) for tracing and flagging for the follow-up of the population's mortality. The total number of records sent to the NHSCR was 3885 , ie, $101(2.5 \%)$ less than the original study total. Of the total sent for tracing, $351(9.0 \%)$ had no record of their survey examination results. Figure 1 summarizes these figures and gives the numbers not traced in each category. The overall success rate for tracing was $97.8 \%$.

The analysis described in this report is predominantly based on the 3458 traced subjects with examination data. The mortality of the 340 traced subjects without examination data is also presented. All the death certificates were coded by the Office of Population Censuses and Surveys according to the eighth revision of the International Classification of Diseases (ICD) for deaths occurring before 1979 and the ninth revision of the ICD for deaths occurring from 1979 onwards.

The Medical Research Council's standardized questionnaire on respiratory symptoms (9), as modified by Roach \& Schilling (10), was administered to the survey subjects. Byssinosis was graded on the basis of the subjects' responses to the questionnaire as follows: grade 0 : no byssinotic symptoms; grade 1/2: occasional chest tightness on the first workday of the week; grade 1: chest tightness on the first workday of every week; and grade 2: chest tightness on the first workday and other days of the week.

The self-reported symptom pattern taken to define "byssinosis" can be found in people not exposed to cotton. It has been estimated that the prevalence of "byssinosis" as measured by the questionnaire among persons without occupational exposure to cotton dust can be as high as $5 \%$ (11). The questionnaire thus recorded as "byssinotic" some individuals who may have had a wider susceptibility to respiratory disease than a strictly specific sensitivity to cotton dust. However, for simplicity of presentation we have referred to individuals "with byssinosis" in place of the more strictly accurate description "reporting byssinotic-type symptoms."

The smoking habits of the subjects were coded to the four categories defined in the footnote to table 8 in the Results section.

At each subject's first survey examination, an employment history was taken. From this history, each subject's total years of employment in the cotton industry prior to the survey was calculated. At subsequent visits to the mills - or at follow-up survey examinations of ex-workers - the dates of leaving cotton work were recorded. About half the population had such a date recorded. For the purposes of this analysis, subjects without a recorded date of leaving were assumed to have left one year after the date of their last examination. The justification for this assumption was that subjects not appearing in the third round of examinations had very probably left the industry. Workers who did appear in the third round, and who were at the time (1971-1974) still working with cotton, will have had a high probability of leaving in the next few years since the industry was contracting very rapidly through the 1970 s.

\section{Calculation of expected deaths}

Person-years were calculated from the date of the first examination to the date of death or emigration or to 31 December 1984, whichever came first.

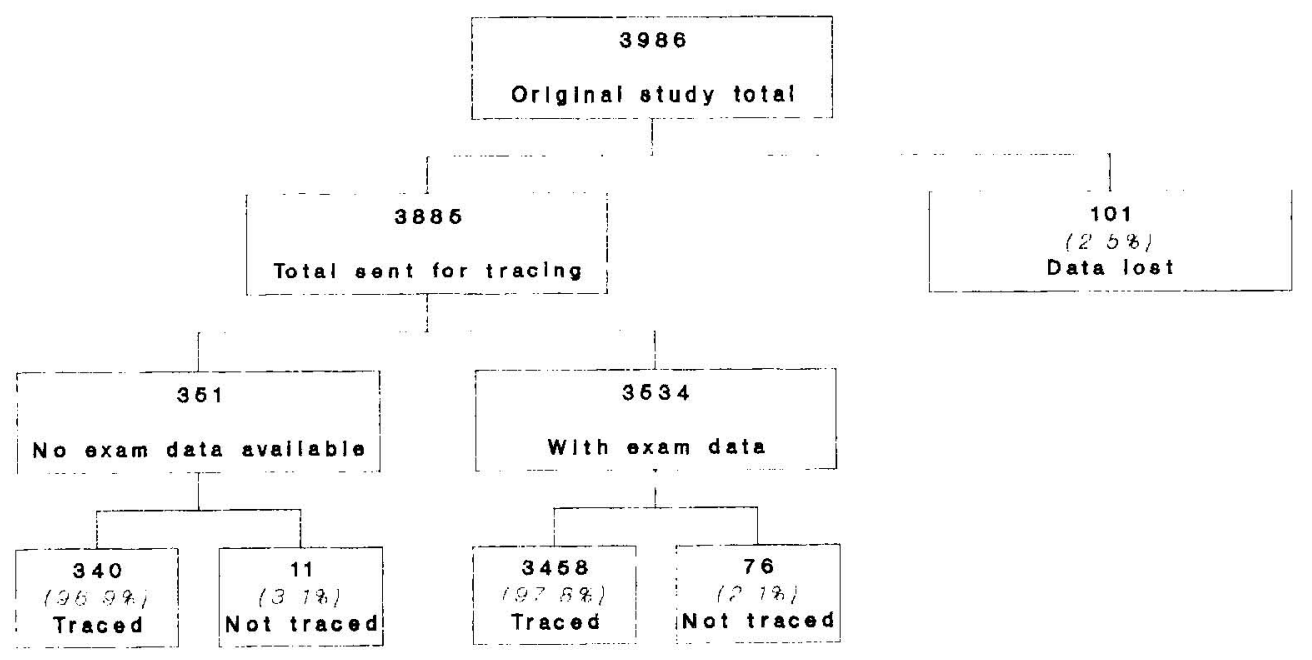

Figure 1. Numbers of subjects by trace and data status. 
The period of observation was divided into the three subperiods 1966-1972, 1973-1978, and 1979-1984; five-year age groups were used from 15 to 84 years with an open-ended upper interval for age 85 years on. National (England and Wales) average sex-, age-, and period-specific death rates were derived from national mortality statistics and applied to the person-years in the calculation of the expected numbers of deaths for a range of causes. The first two years of observation (1966-1967) came prior to the adoption of the eighth revision of the ICD, and the 1968-1972 average rates were used for this period. When the tabulations were prepared, the 1983 mortality data for England and Wales had not been processed, and therefore the 1979-1982 rates were applied to the whole period 1979-1984.

\section{Results}

\section{Overall mortality}

Table 1 shows the major causes of death (20 or more deaths observed or expected) for the main study group (3458 subjects with data from at least one survey medical examination). There was an overall deficit of mortality (583 observed, 684.5 expected). The deficits for all causes and all cancers reached statistical significance at the $1 \%$ level, and that for diseases of the respiratory system was statistically significant at the $5 \%$ level. The deficit in overall mortality was not only due to a lack of deaths from respiratory and circulatory diseases, but was also substantially contributed to by reduced mortality from lung and breast cancer.

Table 1 also shows the standardized mortality ratio (SMR) values for the first five years of follow-up (counting from each individual's date of first examination) and for the subsequent follow-up. There was a substantial difference between the two periods. During the first five years of follow-up the observed numbers of deaths were about one-half the expected numbers; whereas during later periods of follow-up, the numbers of observed deaths were close to those expected, though deaths from respiratory disease remained somewhat low.

Table 2 gives the overall mortality of the $340 \mathrm{sub}$ jects with no available examination data for the same major cause groups as shown in table 1 . The observed deaths from all the major categories were much higher than the number expected, and statistically significant excesses were recorded for all causes and for circulatory disease. For this group of subjects the pattern of mortality in relation to period of follow-up was the reverse of that seen for the main study group, mortality being substantially and significantly raised for the period immediately after entry into the study and close to normal thereafter.

\section{Respiratory and cardiac diseases}

Disease categories of special interest were selected for further analyses of mortality in correlation with cotton exposure and reported byssinotic symptoms. (These analyses were based on the main study group of the 3458 subjects with examination data.) To ensure, as far as possible, that all mortality from respiratory conditions was identified, we included two categories of circulatory disease (pulmonary heart disease and congestive heart failure) which might occur as a consequence of lung disease. Because of the recent suggestion (12) that the deficit of lung cancer in some other studies of cotton workers might be due to a protective effect connected with endotoxins, lung cancer was also included.

Table 1. Mortality from major causes ${ }^{a}$ among the 3458 subjects in the main study group. $(\mathrm{O}=$ observed number of deaths, SMR = standardized mortality ratio, $95 \% \mathrm{Cl}=95 \%$ confidence interval)

\begin{tabular}{|c|c|c|c|c|c|}
\hline \multirow{2}{*}{ Cause } & \multirow{2}{*}{0} & \multirow{2}{*}{ SMR } & \multirow{2}{*}{$95 \% \mathrm{Cl}$} & \multicolumn{2}{|c|}{$\begin{array}{l}\text { SMR by } \\
\text { follow-up }\end{array}$} \\
\hline & & & & $\begin{array}{l}<5 \\
\text { years }\end{array}$ & $\begin{array}{l}\geq 5 \\
\text { years }\end{array}$ \\
\hline All causes & 583 & $85^{* *}$ & $78-92$ & $49^{* *}$ & 94 \\
\hline $\begin{array}{l}\text { All malignant } \\
\text { neoplasms }\end{array}$ & 158 & $81^{* *}$ & $69-95$ & $43^{* *}$ & 92 \\
\hline Lung cancer & 42 & 76 & $54-102$ & $16^{* *}$ & 92 \\
\hline Breast cancer & 14 & 64 & $35-107$ & $0 * *$ & 84 \\
\hline $\begin{array}{l}\text { Circulatory } \\
\text { disease }\end{array}$ & 298 & 91 & $81-102$ & 50 & 100 \\
\hline $\begin{array}{l}\text { Ischemic heart } \\
\text { disease }\end{array}$ & 174 & 90 & $77-105$ & $44^{* *}$ & 101 \\
\hline $\begin{array}{l}\text { Cerebrovascular } \\
\text { disease }\end{array}$ & 69 & 95 & $74-120$ & 75 & 100 \\
\hline $\begin{array}{l}\text { Respiratory } \\
\text { disease }\end{array}$ & 59 & $74^{\circ}$ & $56-95$ & $45^{*}$ & 80 \\
\hline Bronchitis & 20 & 74 & $45-114$ & 29 & 89 \\
\hline
\end{tabular}

a $>20$ deaths observed or expected

* $P<0.05,{ }^{*} P<0.01$

Table 2. Mortality from major causes ${ }^{a}$ among the 340 subjects with no examination data. $10=$ observed number of deaths, SMR = standardized mortality ratio, $95 \% \mathrm{Cl}=95 \%$ confidence interval)

\begin{tabular}{|c|c|c|c|c|c|}
\hline \multirow{2}{*}{ Cause } & \multirow{2}{*}{$\mathrm{O}$} & \multirow{2}{*}{ SMR } & \multirow{2}{*}{$95 \% \mathrm{Cl}$} & \multicolumn{2}{|c|}{$\begin{array}{c}\text { SMR by } \\
\text { follow-up }\end{array}$} \\
\hline & & & & $\begin{array}{c}<5 \\
\text { years }\end{array}$ & $\begin{array}{l}\geq 5 \\
\text { years }\end{array}$ \\
\hline All causes & 69 & $147^{* *}$ & $114-185$ & $247^{* *}$ & 113 \\
\hline $\begin{array}{l}\text { All malignant } \\
\text { neoplasms }\end{array}$ & 21 & 153 & $95-234$ & 195 & 138 \\
\hline Lung cancer & 6 & 189 & $69-408$ & 119 & 215 \\
\hline Breast cancer & 3 & 136 & $28-398$ & 164 & 125 \\
\hline $\begin{array}{l}\text { Circulatory } \\
\text { disease }\end{array}$ & 36 & $163^{*}$ & $114-226$ & $287^{* *}$ & 124 \\
\hline $\begin{array}{l}\text { Ischemic heart } \\
\text { disease }\end{array}$ & 22 & $178^{* *}$ & $111-269$ & $364^{* *}$ & 117 \\
\hline $\begin{array}{l}\text { Respiratory } \\
\text { disease }\end{array}$ & 6 & 117 & $42-246$ & 311 & 52 \\
\hline Bronchitis & 3 & 204 & $41-584$ & $573^{*}$ & 0 \\
\hline
\end{tabular}

$>20$ deaths observed or expected.

$* \mathrm{P}<0.05$ * $\mathrm{P}<0.01$ 
Table 3 shows the mortality for the selected causes for the men and women separately. Deficits were found for all the categories but one, ie, the men showed a nonstatistically significant excess of deaths due to congestive cardiac failure (6 observed, 3.2 expected).

\section{Exposure to cotton}

Table 4 shows mortality by years of employment as cotton workers. There were significant deficits of mortality among the workers with 30 or more years of service in the industry. For all causes the significant deficit occurred for both sexes, but for circulatory disease statistical significance was only reached for the men, although the women showed the same trend. The deficit of lung cancer for these workers was statistically significant when the men and women were combined [ 22 observed, 34.4 expected, SMR 64, $95 \%$ confidence interval $(95 \% \mathrm{CI}) 40-97]$.

Mortality for the workers with fewer years of exposure was much less favorable, and a statistically significant excess of circulatory disease was found in the 15- to 29-year group for the women alone and for both

Table 3. Mortality for selected causes for the men and women in the main study group separately. $\mathrm{O}=$ observed number of deaths, SMR = standardized mortality ratio, $95 \% \mathrm{Cl}=95 \%$ confidence interval)

\begin{tabular}{|c|c|c|c|c|c|c|}
\hline \multirow{2}{*}{ Cause } & \multicolumn{3}{|c|}{ Men } & \multicolumn{3}{|c|}{ Women } \\
\hline & 0 & SMR & $95 \% \mathrm{Cl}$ & 0 & SMR & $95 \% \mathrm{Cl}$ \\
\hline All causes & 316 & $83^{* *}$ & $74-92$ & 267 & $88^{*}$ & $78-100$ \\
\hline Lung cancer & 31 & 75 & $51-106$ & 11 & 79 & $39-141$ \\
\hline $\begin{array}{l}\text { Circulatory } \\
\text { disease }\end{array}$ & 167 & 87 & $74-101$ & 131 & 96 & $80-114$ \\
\hline $\begin{array}{l}\text { Pulmonary heart } \\
\text { disease }\end{array}$ & 1 & 91 & $2-506$ & - & 0 & $0-516$ \\
\hline $\begin{array}{l}\text { Congestive cardiac } \\
\text { failure }\end{array}$ & 6 & 188 & $69-409$ & 1 & 30 & $1-168$ \\
\hline $\begin{array}{l}\text { Respiratory } \\
\text { disease }\end{array}$ & 37 & 74 & $52-102$ & 22 & 74 & $46-111$ \\
\hline
\end{tabular}

${ }^{*} P<0.05, * P<0.01$ sexes combined [101 observed, 80.8 expected, SMR $125,95 \%$ CI 102-152].

The overall pattern of associations with length of cotton exposure showed trends both for deaths due to lung cancer and, though less marked, for deaths due to respiratory disease. In both cases (and for both sexes), the workers with longer exposure showed lower SMR values.

\section{Subjects reporting byssinotic symptoms}

Table 5 shows the mortality for persons who, on the basis of their replies in the examination, were given a grade of $1 / 2$ or higher for the presence of byssinosis. For this group overall mortality was higher than for the total population, and the deficit for circulatory disease was not as apparent in this subgroup, while the SMR values for respiratory disease were raised, but not to a statistically significant level.

\section{Smoking and byssinotic assessment}

Table 6 shows the mortality from lung cancer and circulatory and respiratory diseases in relation to the sex and smoking status of the subjects in the main study group, and the presence of byssinotic symptoms among them. Lung cancer and circulatory disease showed no relation to byssinotic symptoms but were strongly affected, as expected, by smoking. Both the male and female nonsmokers had a statistically significant deficit of lung cancer (SMR 12 and 13, respectively). The male smokers had an SMR of 97, and that of the female smokers was 160 . The pattern for circulatory disease mortality was similar. The male and female nonsmokers' SMR values were 64 and 66, respectively, the corresponding smokers' SMR values being 97 and 151, respectively. The more marked smoker/nonsmoker contrast for the women was a predictable consequence of the lower prevalence of smoking among women (ie, a female smoker is less "typical" than a male smoker).

Table 4. Mortality by years of exposure to cotton in the main study group. $(O=$ observed number of deaths, $E=$ expected number of deaths, SMR = standardized mortality ratio)

\begin{tabular}{|c|c|c|c|c|c|c|c|c|c|c|c|c|c|c|c|c|c|c|}
\hline \multirow{4}{*}{ Cause } & \multicolumn{18}{|c|}{ Years of exposure to cotton } \\
\hline & \multicolumn{6}{|c|}{$<15$ years } & \multicolumn{6}{|c|}{$15-29$ years } & \multicolumn{6}{|c|}{$\geq 30$ years } \\
\hline & \multicolumn{3}{|c|}{ Men } & \multicolumn{3}{|c|}{ Women } & \multicolumn{3}{|c|}{ Men } & \multicolumn{3}{|c|}{ Women } & \multicolumn{3}{|c|}{ Men } & \multicolumn{3}{|c|}{ Women } \\
\hline & $\mathrm{O}$ & $E$ & SMR & $\mathrm{O}$ & $E$ & SMR & 0 & $E$ & SMR & 0 & E & SMR & 0 & $E$ & SMR & 0 & E & SMR \\
\hline All causes & 50 & 51.7 & 97 & 15 & 16.9 & 89 & 104 & 105.6 & 99 & 79 & 71.1 & 111 & 163 & 224.0 & $73^{*+}$ & 173 & 215.0 & $81^{* *}$ \\
\hline Lung cancer & 6 & 4.7 & 127 & - & 0.8 & 0 & 9 & 11.5 & 78 & 5 & 3.9 & 127 & 16 & 25.2 & 63 & 6 & 9.2 & 65 \\
\hline $\begin{array}{l}\text { Circulatory } \\
\text { disease }\end{array}$ & 23 & 24.0 & 96 & 3 & 5.6 & 53 & 62 & 53.3 & 116 & 39 & 27.5 & $142^{\star}$ & 82 & 114.0 & $72^{* *}$ & 89 & 103.0 & 86 \\
\hline $\begin{array}{l}\text { Pulmonary heart } \\
\text { disease }\end{array}$ & - & 0.13 & 0 & - & 0.04 & 0 & - & 0.28 & 0 & - & 0.16 & 0 & 1 & 0.68 & 148 & - & 0.38 & 0 \\
\hline $\begin{array}{l}\text { Congestive cardiac } \\
\text { failure }\end{array}$ & 1 & 0.43 & 232 & - & 0.09 & 0 & 1 & 0.76 & 132 & - & 0.51 & 0 & 4 & 2.0 & 200 & 1 & 2.72 & 37 \\
\hline $\begin{array}{l}\text { Respiratory } \\
\text { disease }\end{array}$ & 8 & 6.5 & 122 & 1 & 1.3 & 76 & 7 & 12.4 & 56 & 5 & 6.0 & 84 & 22 & 31.2 & 71 & 16 & 22.6 & 71 \\
\hline
\end{tabular}

* $P<0.05$, * $P<0.01$. 
For respiratory disease the general pattern was for mortality to increase in relation to both smoking and the occurrence of byssinosis, although the male nonsmokers with byssinotic symptoms $(\mathrm{N}=47)$ had no deaths from respiratory disease (2.1 were expected).

Table 7 shows a further breakdown of respiratory mortality by detailed smoking habits and by the length of cotton exposure. When the data was aggregated by sex and smoking habits, the SMR for subjects without byssinosis decreased with longer exposure, and that for subjects with byssinosis of grade $1 / 2$ or more increased with exposure. This pattern was not maintained when the sexes were grouped separately. Among both the men and the women without byssinosis, exposure and respiratory mortality were negatively related.
Table 5. Mortality of persons with reported symptoms of bys. sinopsis in the main study group. $(O=$ observed number of deaths, $E=$ expected number of deaths, $S M R=$ standardized mortality ratio)

\begin{tabular}{|c|c|c|c|c|c|c|}
\hline \multirow{2}{*}{ Cause } & \multicolumn{3}{|c|}{ Men } & \multicolumn{3}{|c|}{ Women } \\
\hline & 0 & $E$ & SMR & 0 & $E$ & SMR \\
\hline All causes & 107 & 117.8 & 91 & 62 & 68.5 & 91 \\
\hline Lung cancer & 13 & 13.7 & 95 & 2 & 3.4 & 59 \\
\hline $\begin{array}{l}\text { Circulatory } \\
\text { disease }\end{array}$ & 51 & 59.7 & 85 & 29 & 30 & 97 \\
\hline $\begin{array}{l}\text { Pulmonary heart } \\
\text { disease }\end{array}$ & 1 & 0.34 & 297 & - & 0.14 & 0 \\
\hline $\begin{array}{l}\text { Congestive cardiac } \\
\text { failure }\end{array}$ & 2 & 0.83 & 240 & - & 0.67 & 0 \\
\hline $\begin{array}{l}\text { Respiratory } \\
\text { disease }\end{array}$ & 15 & 14.3 & 105 & 8 & 6.4 & 124 \\
\hline Bronchitis & 3 & 6.1 & 49 & 3 & 1.5 & 206 \\
\hline
\end{tabular}

Table 6. Observed (O) number of deaths and the standardized mortality ratio (SMR) for lung cancer, circulatory disease, and respiratory disease by smoking and byssinosis status for the men and women in the main study group separately.

\begin{tabular}{|c|c|c|c|c|c|c|c|c|}
\hline \multirow{3}{*}{ Disease } & \multicolumn{4}{|c|}{ Men } & \multicolumn{4}{|c|}{ Women } \\
\hline & \multicolumn{2}{|c|}{ Smokers } & \multicolumn{2}{|c|}{ Nonsmokers } & \multicolumn{2}{|c|}{ Smokers } & \multicolumn{2}{|c|}{ Nonsmokers } \\
\hline & 0 & SMR & 0 & SMR & 0 & SMR & 0 & SMR \\
\hline \multicolumn{9}{|l|}{ Lung cancer } \\
\hline $\begin{array}{l}\text { Persons with byssinosis } \\
\text { Persons without byssinosis }\end{array}$ & $\begin{array}{l}11 \\
17\end{array}$ & $\begin{array}{r}106 \\
92\end{array}$ & 1 & $\begin{array}{c}54 \\
0^{* *}\end{array}$ & $\begin{array}{l}2 \\
8\end{array}$ & $\begin{array}{l}114 \\
181\end{array}$ & $\overline{1}$ & $\begin{array}{c}0 \\
17^{*}\end{array}$ \\
\hline \multicolumn{9}{|l|}{ Circulatory disease } \\
\hline $\begin{array}{l}\text { Persons with byssinosis } \\
\text { Persons without byssinosis }\end{array}$ & $\begin{array}{l}44 \\
85\end{array}$ & $\begin{array}{l}97 \\
97\end{array}$ & $\begin{array}{r}2 \\
22\end{array}$ & $\begin{array}{l}24^{*} \\
75\end{array}$ & $\begin{array}{l}21 \\
55\end{array}$ & $\begin{array}{l}171^{*} \\
144^{*}\end{array}$ & $\begin{array}{r}7 \\
45\end{array}$ & $\begin{array}{l}45^{*} \\
71^{*}\end{array}$ \\
\hline \multicolumn{9}{|l|}{ Respiratory disease } \\
\hline $\begin{array}{l}\text { Persons with byssinosis } \\
\text { Persons without byssinosis }\end{array}$ & $\begin{array}{l}13 \\
16\end{array}$ & $\begin{array}{r}123 \\
68\end{array}$ & $\overline{4}$ & $\begin{array}{r}0 \\
51\end{array}$ & $\begin{array}{l}4 \\
9\end{array}$ & $\begin{array}{l}153 \\
105\end{array}$ & $\begin{array}{l}4 \\
5\end{array}$ & $\begin{array}{c}118 \\
36^{*}\end{array}$ \\
\hline
\end{tabular}

${ }^{*} \mathrm{P}<0.05,{ }^{* *} \mathrm{P}<0.01$.

Table 7. Observed $(O)$ number of deaths from respiratory disease and the standardized mortality ratio (SMR) by smoking habit, byssinosis status, and length of employment in the cotton industry for the men and women in the main study group separately.

\begin{tabular}{|c|c|c|c|c|c|c|c|}
\hline \multicolumn{4}{|c|}{ With byssinosis } & \multicolumn{4}{|c|}{ Without byssinosis } \\
\hline & jears & & ears & & jears & & lears \\
\hline 0 & SMR & 0 & SMR & 0 & SMR & 0 & SMR \\
\hline
\end{tabular}

Smokers

$$
\begin{gathered}
\geq 15 \text { cigarettes } / d \\
\text { Men } \\
\text { Women } \\
<15 \text { cigarettes } / d \\
\text { Men } \\
\text { Women } \\
\text { Nonsmokers }
\end{gathered}
$$

\begin{tabular}{|c|c|c|c|c|c|c|c|}
\hline- & 0 & 7 & 146 & 6 & 152 & 2 & 40 \\
\hline 1 & 416 & 1 & 213 & 2 & 182 & 1 & 61 \\
\hline $\begin{array}{l}2 \\
1\end{array}$ & $\begin{array}{r}86 \\
127\end{array}$ & $\begin{array}{l}4 \\
1\end{array}$ & $\begin{array}{r}104 \\
89\end{array}$ & $\begin{array}{l}6 \\
3\end{array}$ & $\begin{array}{r}83 \\
126\end{array}$ & $\begin{array}{l}2 \\
3\end{array}$ & $\begin{array}{l}27 \\
87\end{array}$ \\
\hline-1 & $\begin{array}{r}0 \\
192\end{array}$ & $\overline{3}$ & $\begin{array}{r}0 \\
105\end{array}$ & $\begin{array}{l}3 \\
1\end{array}$ & $\begin{array}{l}84 \\
27\end{array}$ & $\begin{array}{l}1 \\
4\end{array}$ & $\begin{array}{l}23 \\
39\end{array}$ \\
\hline
\end{tabular}

$$
\text { Men }
$$

Women

Smokers and nonsmokers combined

Men

Women

Men and women combined

\begin{tabular}{rrrrrrrr}
2 & 45 & 11 & 133 & 15 & 102 & 5 & 30 \\
3 & 194 & 5 & 112 & 6 & 83 & 8 & 52 \\
5 & 84 & 16 & 126 & 21 & 96 & 13 & 40 \\
\hline
\end{tabular}


Among the persons with byssinosis, the men showed a strong positive relation and the women a weaker negative one. For each sex the patterns were maintained across all the smoking categories.

\section{Analysis of byssinosis levels}

To explore the effects of age, smoking, and cotton exposure on symptoms of byssinosis, a logistic regression model was fitted predicting the prevalence of byssinosis (grade 1/2 or more) in terms of age, years of cotton exposure, and smoking. An additional factor was also defined to identify ex-smokers as a separate category.

Table 8. Analysis of deviance for regression models of the prevalence of byssinosis.

\begin{tabular}{lccc}
\hline Model & Variable $^{\mathrm{a}}$ & $\begin{array}{l}\text { Change in deviance/ } \\
\text { degrees of freedom }\end{array}$ & $\begin{array}{c}\text { Approximate } \\
\text { P-value }\end{array}$ \\
\hline \multicolumn{4}{c}{ Mean } \\
(Total deviance/df $=507.0 / 143)$ \\
2 & SMOK & $74 / 3$ & $<0.001$ \\
3 & AGE & $201 / 5$ & $<0.001$ \\
4 & XCOT & $103 / 5$ & $<0.001$ \\
3 & XCOT & $268 / 5$ & $<0.001$ \\
5 & AGE & $36 / 5$ & $<0.001$ \\
\hline & XSMO & $2.1 / 1$ & 0.15 \\
\hline
\end{tabular}

a All variables are factors:

SMOK (Smoking, four levels: nonsmoker; $<15$ cigarettes/d (and or $<80 \mathrm{~g}$ tobacco/week); $15-24$ cigarettes/d (and/or < $160 \mathrm{~g}$ tobacco/week); and $\geq 25$ cigarettes/d (and/or $>160 \mathrm{~g}$ tobacco/week).

AGE (Age, six levels: $<20,30-, 40-, 50-, 60-, \geq 70$ years).

XCOT (Exposure to cotton, six levels: $<10,10-, 20-, 30-$, $40-, \geq 50$ years).

XSMO (Ex/current smoker, two levels. All ex-smokers were assigned the 15-24 cigarettes/d level on SMOK).

Byssinosis prevalence was modeled as the logit of SMOK+ $A G E+X C O T$

Table 9. Observed $(\mathrm{O})$ number of deaths from lung cancer and the standardized mortality ratio (SMR) by smoking habits and length of cotton exposure for the men and women in the main study group separately.

\begin{tabular}{|c|c|c|c|c|c|c|}
\hline & \multicolumn{6}{|c|}{ Cotton exposure } \\
\hline & \multicolumn{2}{|c|}{$\begin{array}{l}<20 \\
\text { years }\end{array}$} & \multicolumn{2}{|c|}{$\begin{array}{c}20-40 \\
\text { years }\end{array}$} & \multicolumn{2}{|c|}{$\begin{array}{c}>40 \\
\text { years }\end{array}$} \\
\hline & 0 & SMR & 0 & SMR & 0 & SMR \\
\hline \multicolumn{7}{|l|}{ Smokers } \\
\hline \multicolumn{7}{|c|}{$\geq 15$ cigarettes $/ d$} \\
\hline $\begin{array}{l}\text { Men } \\
\text { Women }\end{array}$ & $\begin{array}{l}5 \\
1\end{array}$ & $\begin{array}{l}176 \\
222\end{array}$ & $\begin{array}{l}7 \\
3\end{array}$ & $\begin{array}{l}118 \\
265\end{array}$ & $\begin{array}{l}4 \\
1\end{array}$ & $\begin{array}{l}110 \\
256\end{array}$ \\
\hline \multicolumn{7}{|c|}{$<15$ cigarettes $/ \mathrm{d}$} \\
\hline $\begin{array}{l}\text { Men } \\
\text { Women }\end{array}$ & $\stackrel{4}{-}$ & $\begin{array}{r}120 \\
0\end{array}$ & $\begin{array}{l}5 \\
4\end{array}$ & $\begin{array}{r}67 \\
162\end{array}$ & $\begin{array}{l}3 \\
1\end{array}$ & $\begin{array}{l}52 \\
96\end{array}$ \\
\hline \multicolumn{7}{|l|}{ Nonsmokers } \\
\hline $\begin{array}{l}\text { Men } \\
\text { Women }\end{array}$ & - & $\begin{array}{l}0 \\
0\end{array}$ & $\begin{array}{l}1 \\
1\end{array}$ & $\begin{array}{l}29 \\
31\end{array}$ & - & $\begin{array}{l}0 \\
0\end{array}$ \\
\hline
\end{tabular}

Table 8 shows the analysis of deviance for the chosen model. Age, years of cotton exposure, and smoking each made independent and highly significant contributions to the model. The adjustment for ex-smokers was not statistically significant. When the ex-smoker adjustment was included, the corresponding model parameter gave ex-smokers predicted byssinosis rates between those of light and medium smokers.

Figure 2 displays the predicted values from this model in terms of years of cotton exposure for subjects aged $40-49$ years. For clarity only the heavy, light, and nonsmoker curves are shown, the medium smoking category curve lies between the heavy and light smoker curves.

\section{Lung cancer and cotton exposure}

Table 9 shows lung cancer mortality in terms of cotton exposure. There was a consistent pattern of decreasing SMR values with increasing length of exposure in all the smoking categories (except for nonsmokers and female heavy smokers, for whom the numbers were too small to indicate a trend).

\section{Discussion}

Recent debate about the nature of byssinosis centers on the question of the permanence of its impact on affected workers' health. There is no doubt that exposure to cotton dust leads to acute respiratory changes in some workers. Numerous studies have demonstrated that this acute effect can be observed both in terms of subjective reports of the typical "Monday morning chest tightness," and the objective pre- to postshift

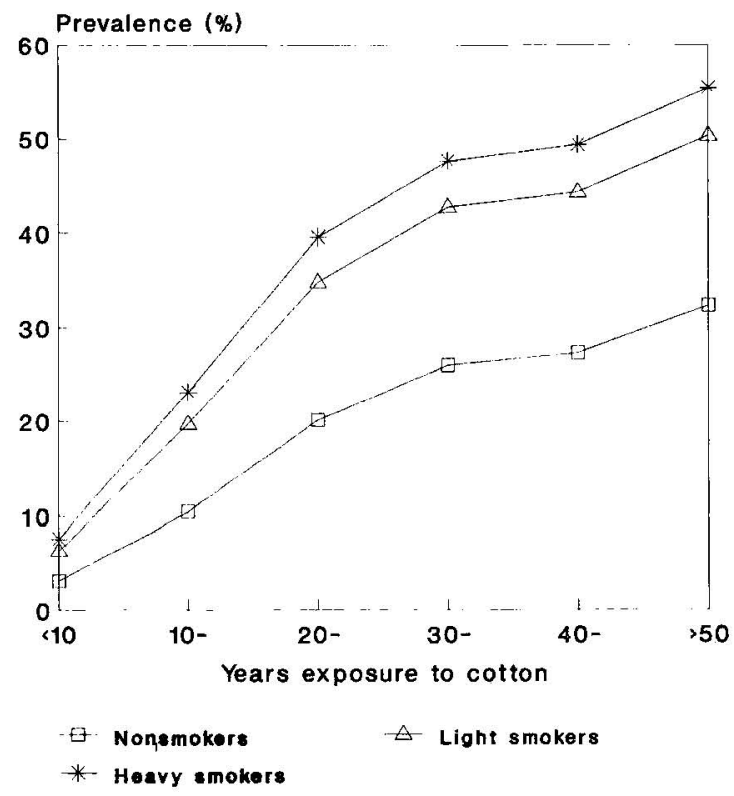

Figure 2. Fitted values of byssinosis prevalence by years of exposure to cotton for the workers aged $40-49$ years. 
changes in respiratory performance. Some studies (including the original morbidity analyses of this population) have also shown that the rate of lung function loss, and base-line (preshift) lung function, is lower among long-term cotton workers than among the general population. Nevertheless, it has been argued $(1,13-15)$ that the existence of these effects does not prove that byssinosis is, in fact, permanently and significantly disabling.

The evidence of published analyses of mortality among cotton workers $(15-20)$ is equivocal as to whether cotton workers' mortality is detectably worse than that of appropriate reference groups. None of these studies were able to allow for the effects of smoking.

The mortality data presented in this report was derived from a follow-up of a cross-sectional or census population of cotton workers. Individual subjects were followed for a period ranging from 13 to 18 years. The data on cotton exposure relates predominantly to time prior to recruitment of an individual into the study.

The low overall mortality of the main study population reached statistical significance at the $1 \%$ level, but this overall deficit was due to the very low mortality in the first five years.

Because of its cross-sectional nature, the population may well have experienced selection bias, and this bias, along with the healthy worker effect enhanced by the relatively short period of follow-up (maximum 18 years), may well have been responsible for much of the deficit in mortality that was observed. This deficit was still present when the results for subjects with no examination data were included, and the pattern in relation to follow-up period was maintained, though the difference between the first five years and subsequent years was reduced. It is clear that - by chance, or otherwise - the subjects without examination data included a disproportionate number of the unhealthy members of the initial population. However their relatively small number, and the fact that their mortality for respiratory disease-the category of most interest - was close to expectation (6 observed, 5.3 expected, SMR 117), gives some assurance that the analyses based on the main study group were not seriously distorted.

The interpretation of the relationship of respiratory mortality to years of exposure to cotton is complicated by the fact that cotton has an acute - and subjectively apparent - effect that will produce a tendency for workers so affected to leave cotton work (if possible). When this process operates, the work force is continuously purged of individuals susceptible to the effects of cotton dust, and thus the damage to their respiratory health is curtailed.

At first sight, the relationships between byssinosis, respiratory mortality, and years of exposure to cotton in this population are contradictory. The presence of byssinotic symptoms was strongly and positively related to cotton exposure after smoking and age were controlled for (table 8, figure 2). Byssinosis was positively related - though the numbers were small - to respiratory mortality (table 6) and remained so after control for smoking and sex (table 7). But cotton exposure was strongly and negatively related to respiratory mortality (table 4). The key to this puzzle is the selection effect that has already been outlined - or, more accurately, its implications for the "survivors." Individuals who have spent, say, 40 years in exposure to cotton and who have no byssinotic symptoms are, evidently, not very sensitive to the effects of cotton dust and, to this extent at least, have more robust respiratory systems than persons with symptoms. (Sensitivity to cotton dust may be an indicator of a more general respiratory sensitivity.) According to this assumption one would expect the respiratory mortality of nonsymptomatic individuals in a cross-sectional survey to fall with increasing cotton exposure and for normal respiratory death rates to apply only to those persons with the shorter lengths of exposure. This is exactly the pattern shown for the nonbyssinotic population in table 7, for both sexes, and with some consistency over all smoking categories (although the "normal" SMR values for respiratory disease are, of course, greater than 100 for smokers). For individuals with byssinotic symptoms the picture is less clear. For the men, and for both sexes combined, the SMR for respiratory disease increased with increasing cotton exposure; but for the women the pattern was reversed (though based on only eight deaths in comparison with the 13 among the men).

In considering these data, the effects of selection must be recalled. If those who are affected leave the industry before their exposure to cotton has done all the damage it might, the full potential effects will (happily) rarely be seen, and the analysis of mortality among symptomatic individuals will show a weaker relationship than otherwise. In addition it is likely that part-time or interrupted working patterns are more common among women than men so that, for women, the length of employment in the industry is a less satisfactory measure of exposure than is the case for men.

The effects of smoking on mortality are demonstrated in table 6 . They were broadly as expected with raised levels of circulatory disease and lung cancer for smokers as compared with nonsmokers. However the male smokers' SMR values were lower for both causes of death and less different from those of the nonsmokers than would normally be seen. This observation is probably explained by the fact that, while the prevalence of smoking in this population was close to average, the level of consumption among the men was lower. The proportion of male smokers consuming $<15$ cigarettes per day was $52 \%$ for this population and was $35 \%$ for the general population at the time of the original survey (21). This low tobacco consumption is probably due to restrictions on smoking in cotton mills. The female smokers in this population did not have a lower tobacco consumption than the general 
(female) population, presumably because at average levels of female cigarette consumption (much lower than men's) the restrictions on smoking in the mills have less impact. The percentage of women smoking $<15$ cigarettes per day was $62 \%$ for the cotton workers, ie, the same percentage as for the general female population.

These considerations of restrictions on smoking are obviously relevant to the question of whether exposure to endotoxins in cotton dust have a protective effect against lung cancer, as suggested by Enterline et al (12). The strong trends of decreasing lung cancer mortality with increasing length of cotton exposure shown in table 9 suggest that there may indeed be such an effect. Since this is a comparison between smoking cotton workers, their level of consumption relative to that of the general population is not relevant except to the extent that ex-cotton workers' smoking consumption may increase after they cease cotton work. There is some evidence that this may be the case, for women at least. Among the women last seen as ex-workers, $16 \%$ had increased their consumption from that recorded in the first examination, and $8 \%$ had reduced their consumption. For the men there was very little difference (21\% increase, $19 \%$ decrease). The median gap between the first examination and the last for these workers was 5.8 years. These changes do not seem sufficiently large to explain the strong trends observed, particularly since early smoking behavior is a much more powerful determinant of lung cancer mortality than more recent smoking.

\section{Concluding remarks}

Exposure to cotton dust does affect the risk of death from respiratory disease, but only in susceptible individuals. Smoking exacerbates this effect. The acute byssinotic response is (weakly) predictive of those at increased risk.

The study provides support for the hypothesis that exposure to cotton dust reduces the risk of lung cancer, perhaps through the action of the associated endotoxins.

\section{Acknowledgments}

We thank the staff of the National Health Service Central Register for their efficient help in tracing the study population and providing coded copies of the death certificates. We are also grateful to our own data management team for their continuing work to maintain and update the survey data; and particularly to Ms A Fletcher and Ms LM Naylor, who were respon- sible for checking and preparing the data for the present analysis.

\section{References}

1. Elwood PC, McAulay IR, Elwood JH. The flax industry in Northern Ireland twenty years on. Lancet 1982 ; $1: 1112-4$.

2. Schilling RSF. Long term respiratory disability in cotton flax workers. Lancet 1982;2:330.

3. Medical Research Council, Epidemiology Unit. New light on byssinosis. Papers presented at a meeting at the University Hospital of Wales, 1985.

4. Tockman MS, Baser M. Is cotton dust exposure associated with chronic effects? Am Rev Respir Dis 1984; 130:1-3.

5. Fox AJ, Tombleson JBL, Watt A, Wilkie AG. A survey of respiratory disease in cotton operatives: Part I. symptoms and ventilation test results. $\mathrm{Br} \mathrm{J}$ Ind Med 1973;30:42-7.

6. Fox AJ, Tombleson JBL, Watt A, Wilkie AG. Part II: symptoms, dust estimations and the effect of smoking habit. Br J Ind Med 1973;30:48 - 53.

7. Cotes JE, Malhotra MS. Differences in lung function between Indians and Europeans. J Physiol 1965;177: $17-8$.

8. Cotes JE. Lung function. Oxford: Blackwell, 1968.

9. MRC Committee on the Aetiology of Chronic Bronchitis. Standardized questionnaires on respiratory symptoms. Br Med J 1960;2:1665.

10. Roach SA, Schilling RSF. A clinical and environmental study of byssinosis in the Lancashire cotton industry. Br J Ind Med 1960;17:1—9.

11. Engelberg AL, Piacitelli GM. Medical and industrial hygiene characterization of the cotton waste utilization industry. Am J Ind Med 1985;7:93-108.

12. Enterline PE, Keleti G, Skyora JL, Lange JH. Endotoxins, cotton dust and cancer. Lancet 1985;2:934.

13. Elwood PC, Pemberton J, Merrett JD, Carey GCR, McAulay IR. Byssinosis and other respiratory symptoms in flax workers in Northern Ireland. $\mathrm{Br} \mathbf{J}$ Ind Med 1965;22:27-37.

14. National Research Council Committee on Byssinosis. Byssinosis: clinical and research issues. Washington DC: National Academy Press, 1982.

15. Elwood PC, Thomas HF, Sweetnam PM, Elwood JH. The mortality of flax workers. Br J Ind Med 1982;39: $18-22$.

16. Henderson V, Enterline PE. An unusual mortality experience in cotton textile workers. J Occup Med 1973; 15:717-9.

17. Daum SM, Seidman H, Heimann H, Damon F, Richter E, Selikoff IJ. Mortality experience of a cohort of cotton textile workers. Cincinnati, OH: National Institute for Occupational Safety and Health, 1975. (Final progress report on contract no HSM 99-72-71 (NIOSH).)

18. Berry G, Molyneux MKB. A mortality study of workers in Lancashire cotton mills. Chest 1981;79:11S-5S.

19. Merchant JA, Ortmeyer C. Mortality of employees of two cotton mills in North Carolina. Chest 1981;79: $6 \mathrm{~S}-11 \mathrm{~S}$.

20. Enterline PE. Mortality among asbestos products workers in the United States. Ann NY Acad Sci 1965;132: $156-65$.

21. Lee PN. Statistics of smoking in the UK. London: Tobacco Research Council, 1976.

Received for publication: 27 February 1989 